UNDERGRADUATE RESEARCH IN NATURAL AND CLINICAL SCIENCE AND TECHNOLOGY (URNCST) JOURNAL Read more URNCST Journal articles and submit your own today at: https://www.urncst.com

\title{
Examining the Use of Electroencephalography for the Diagnosis of Alzheimer's Disease and Mild Cognitive Impairment
}

\author{
Matthew Connor So, BHSc Student [1]*, Zahra Abdallah, BHSc Student [1], Jia Hui Du, \\ BHSc Student [1] \\ [1] Faculty of Health Sciences, McMaster University, Hamilton, Ontario, Canada L8S 4L8 \\ *Corresponding Author: som5@mcmaster.ca
}

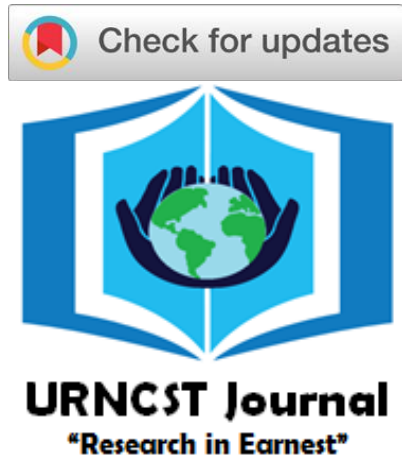

\begin{abstract}
Introduction: Alzheimer's disease is a type of dementia characterized by a buildup of $\beta$-amyloid plaques and neurofibrillary tangles. Prior to the development of Alzheimer's disease, patients may experience mild cognitive impairment, characterized by a decline in cognitive abilities while maintaining independent function. Electroencephalography has shown promise as a clinical predictor of mild cognitive impairment. The purpose of this study is to review the existing literature on clinical biomarkers using resting-state electroencephalography or event-related potentials to differentiate Alzheimer's disease or mild cognitive impairment from normal aging.

Methods: A search of primary research articles was conducted in PubMed. Selected articles examined mild cognitive impairment and Alzheimer's disease utilising electroencephalography, event-related potential data, and resting-state data. Reviews, conference abstracts, and studies without human controls were excluded.

Results: Our search identified 100 and 125 records on resting-state and event-related potential data, respectively. The most common findings from resting-state studies included a reduction in alpha power, an increase in delta and theta power, a reduction in signal complexity, and differences in functional connectivity. The most common findings from event-related potential studies included reduction in P3 wave amplitude, as well as latency in both P3 and N2 waves.

Discussion: Resting-state and event-related potential electroencephalography studies indicate distinct changes in oscillatory brain activity and waveform shape which indicate distinct differences in MCI or AD compared to HC which may be clinically relevant.

Conclusion: There is evidence to support the use of certain electroencephalographic biomarkers for the diagnosis of Alzheimer's disease or mild cognitive impairment. Future research should seek to examine how best to apply these findings in a clinical setting.
\end{abstract}

Keywords: Alzheimer's disease; mild cognitive impairment; electroencephalography; resting-state; event-related potential; literature review; aging

\section{Introduction}

Alzheimer's disease (AD) is a common type of dementia, characterized by the accumulation of plaques consisting of the protein fragment amyloid- $\beta$, as well as aggregates of hyperphosphorylated tau proteins [1]. The initial stages of this disease are marked by impaired encoding of new memories [2]. Later stages are denoted by cognitive and behavioural decline, such as impairments in language [3]. Mild cognitive impairment (MCI) is a stage in which an individual experiences a decline in cognitive abilities (such as recollection and familiarity) but maintains independent function. Individuals with MCI are at an increased risk of progressing to AD [4]. Early identification is important, as clinical interventions may reduce the risk of progression to dementia [3,4]. Although there are treatments for $\mathrm{AD}$ symptoms, such as cholinesterase inhibitors, there is currently no cure for MCI or AD [3]. Nevertheless, identifying individuals with MCI is essential in the pursuit of developing interventions and treatments to prevent or slow the progression to $\mathrm{AD}[3,4]$.

Currently, a combination of clinical expertise and neuropsychological assessments is utilized for diagnosis. The criteria for MCI diagnosis include: 1) A patientidentified cognitive complaint, 2) an objective demonstration of cognitive impairment 3 ) having general normal cognition outside the primarily impaired domain(s) 4) not fitting the criteria for AD or other dementias [3]. Neuropsychological assessments are central to the diagnosis of AD [5,6]. For example, the National Institute of Neurological and Communicative Disorders and Stroke-Alzheimer's Disease and Related Disorders Association (NINCDS-ADRDA) tool is one of the oldest and most reliable tools for AD diagnosis. 
UNDERGRADUATE RESEARCH IN NATURAL AND CLINICAL SCIENCE AND TECHNOLOGY (URNCST) JOURNAL Read more URNCST Journal articles and submit your own today at: https://www.urncst.com

This tool has a sensitivity of $81 \%$ and a specificity of $70 \%$ [6]. This implies that the tool returns a positive result $81 \%$ of the time on persons who truly have $\mathrm{AD}$, and returns a negative result $70 \%$ of the time on persons who do not truly have AD. Given the low specificity of AD diagnostic tools, there is room for improvement to correctly identify patients with $\mathrm{AD}$, and even more so for MCI.

\section{Neuropsychological Evaluation versus}

\section{Electroencephalography}

The assessments used to determine the neurological and cognitive functions of the human brain can generally be classified into two categories. Assessments such as magnetic resonance imaging, electroencephalography (EEG), and cerebrospinal fluid analysis via lumbar puncture can be considered neurological in nature. These assessments seek to ascertain the physical manifestations of physiological changes occurring in disease or disorders, which then influence the management and treatment of symptoms [7]. Neurologic tests differ from neuropsychological evaluations, which seek to evaluate the functional deficits in cognition and behaviour associated with disease. This is primarily achieved through task-based or question-based evaluations. Subsequently, results are used to guide the development of treatments and therapies meant to address functional and cognitive deficiencies associated with disease.

Comparisons between these two broad categories of assessments are challenging, as they serve different functions. However, a broad assessment is still possible. We note that the average neuropsychological assessment ranges between 2 to 6 hours, and can last even longer depending on the severity and complexity of disease $(8,9)$. Comparatively, the average EEG ranges from 20 to 60 minutes, far shorter than a neuropsychological assessment [10]. This may be combined with the fact that neuropsychological evaluation is far more dependent on the ability of the experiment to ask questions and for the patient to respond to said questions. Barriers in language and understanding present a far greater challenge in neuropsychological assessments, and given the much longer assessment times, can lead to greater frustrations on the part of the participants [11]. Thus, from the broad perspective of accessibility, EEG and other neurological tests present far shorter and less frustrating experiences for participants.

EEG provides accurate, real-time data regarding the physical attributes of the brain while being sensitive to subtle changes in neural function that cannot be detected in neuropsychological testing. [12]. Furthermore, accurate assessments of temporal relations could be made with EEG and other neurological tests, allowing for the provision of additional insights into the physical mechanism observed with disease [12].

\section{Electroencephalography Fundamentals}

To explore EEG in the context of MCI, it is imperative to understand the fundamentals of this imaging tool. Neurons comprise the primary information processing unit of the brain. Information is relayed from one neuron to another through the firing of action potentials. An action potential is a sudden depolarization of a neuron characterized by a sharp increase in the voltage of a neuron (more positive). This results in an electrical impulse that is sent along the axon and is subsequently received by another neuron. EEG is used to measure the electrical activity of the brain by measuring the voltage associated with different brain regions across time. Most commonly, this is done in a non-invasive way by placing electrodes on the scalp of a participant [13]. Therefore, electrical signals from the brain must transmit through various layers of tissue in the skull before being recorded by an electrode.

An EEG study seeks to understand the electrical processes occurring in the brain. However, during EEG measurement, several factors (termed "artifacts") may interfere with the measurement of desired electrical activity. Line noise is an artifact caused by measurement of the activity of a connected electrical power grid [14]. Blinking and subject movements result in distinct patterns of brain activity that can interfere with resting-state EEG [15]. Often, EEG software will reduce noise using a band-pass filter, a method intended to remove frequencies above or below defined thresholds. Another preprocessing method useful for a wide variety of artifact corrections utilizes independent component analysis to determine statistically independent component processes that could generate the observed electrode patterns.

While many techniques can be used to analyze EEG data, several are more common in the literature. Timedomain EEG data can be visualized as a plot with the neural voltage on the $y$-axis, and the time since observation starts on the x-axis. Figure 1 illustrates time-domain EEG data collected from several electrodes at once. The fast Fourier transform (FFT) decomposes time-domain data into frequency-domain data by determining a series of sine and cosine functions of different frequencies which may be added to obtain the time-domain data. [16]. The FFT can be used to determine the power spectral density, a measure of the strength of an EEG signal at a given frequency. For example, a slowly oscillating EEG signal (which would appear to have a higher period or lower frequency), would typically be found during states of lower alertness or sleep. Consequently, this signal would be expected to have a higher spectral power at lower frequencies. EEG frequency bands can be divided into delta (1-4 Hz), theta (4-8 Hz), alpha (8$12 \mathrm{~Hz})$, beta $(12-25 \mathrm{~Hz})$, and gamma $(>25 \mathrm{~Hz})$ frequency bands [17].

Figure 2 illustrates a power spectrum determined from EEG data, showing a peak in the spectral power at $10 \mathrm{~Hz}$ (within the alpha frequency band). Figure 3 illustrates the aforementioned frequency bands typically used in EEG analyses. Techniques investigating the power found in different frequency bands are commonly used in the restingstate EEG literature, which measures neural activity in the 
UNDERGRADUATE RESEARCH IN NATURAL AND CLINICAL SCIENCE AND TECHNOLOGY (URNCST) JOURNAL Read more URNCST Journal articles and submit your own today at: https://www.urncst.com

absence of outside stimuli [18]. Therefore, resting-state EEG is thought to measure the intrinsic activity of the brain, particularly in areas known as resting-state networks [19].
Abnormalities in the power spectrum can be characteristic of several neurological disorders, such as AD.

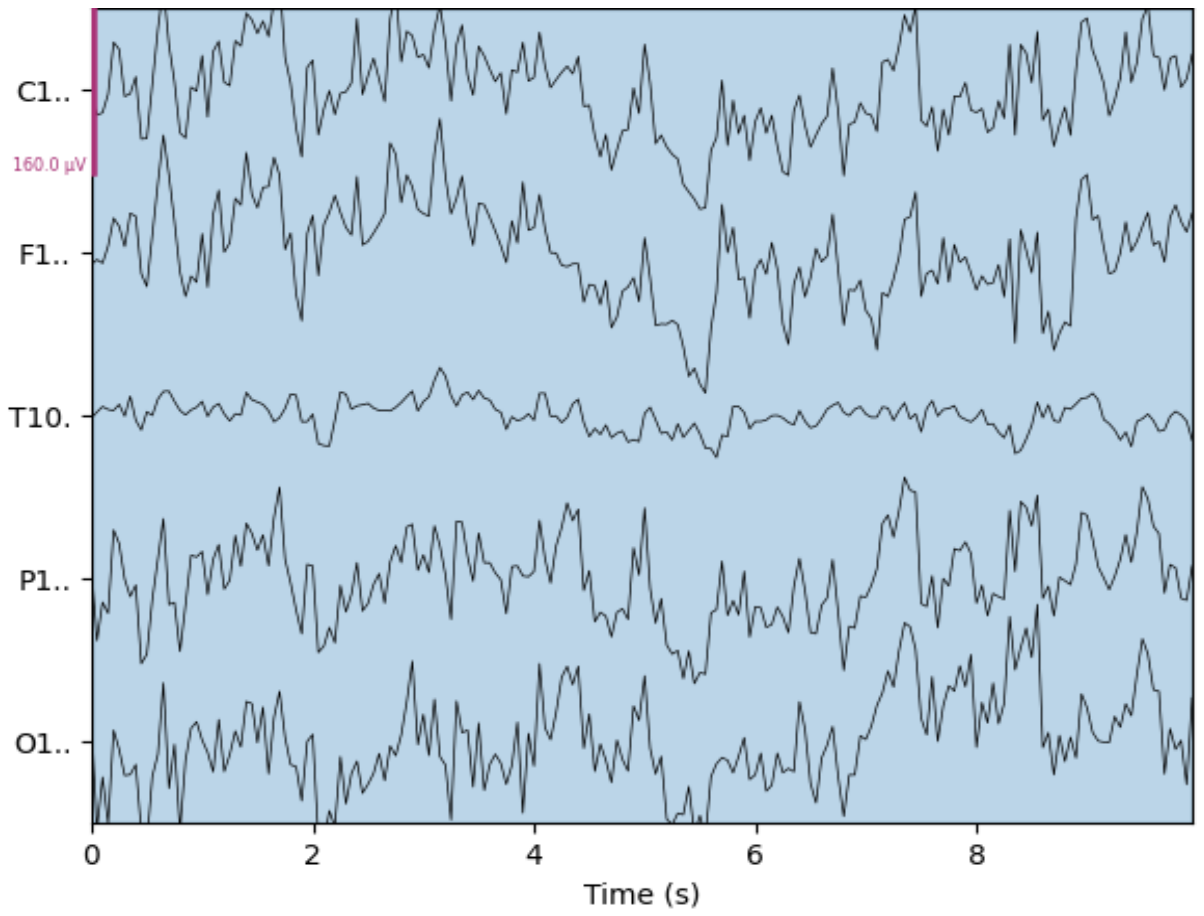

Figure 1. An example of time-domain eyes-closed resting-state EEG data. Each electrode is labelled with its name (C1.., F1.., T10. P1.., O1..), with the vertical fluctuations representing changes in electrical voltage. Data obtained from a single subject in the BCI2000 dataset and analyzed with MNE-Python [20,21].

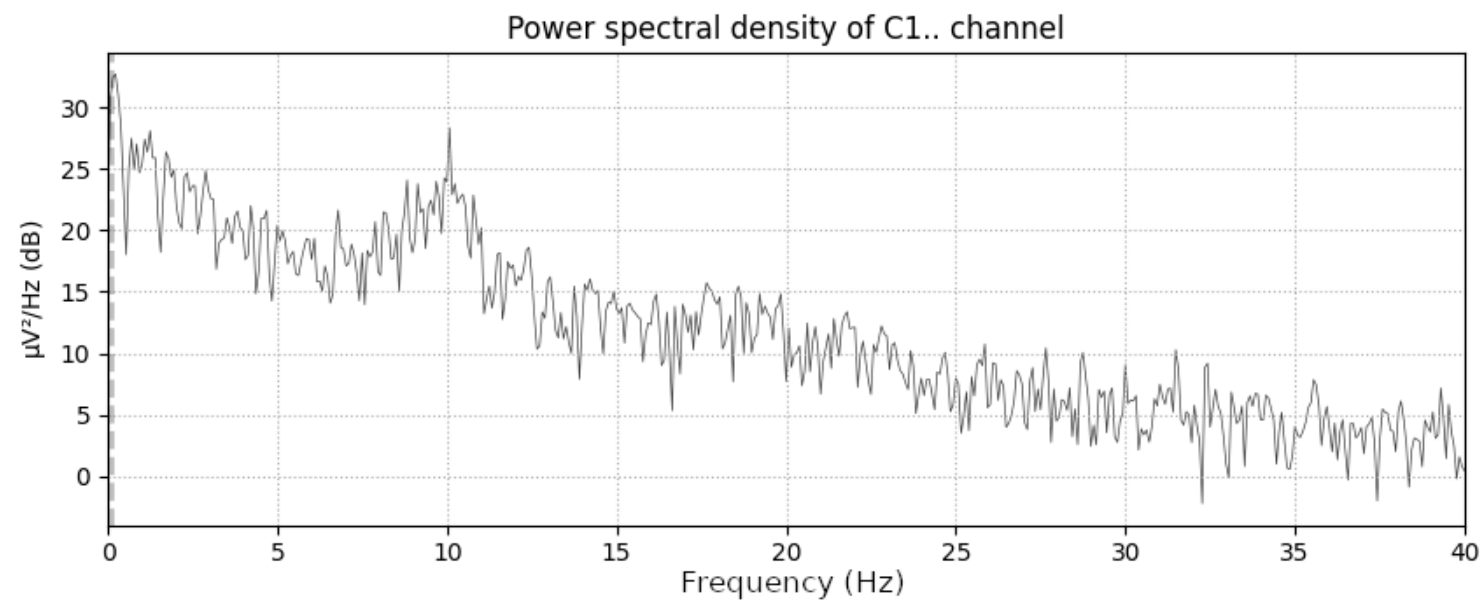

Figure 2. The power spectral density of a selected EEG channel. The highest power can be found at about $10 \mathrm{~Hz}$ (in the alpha frequency band). 
UNDERGRADUATE RESEARCH IN NATURAL AND CLINICAL SCIENCE AND TECHNOLOGY (URNCST) JOURNAL Read more URNCST Journal articles and submit your own today at: https://www.urncst.com

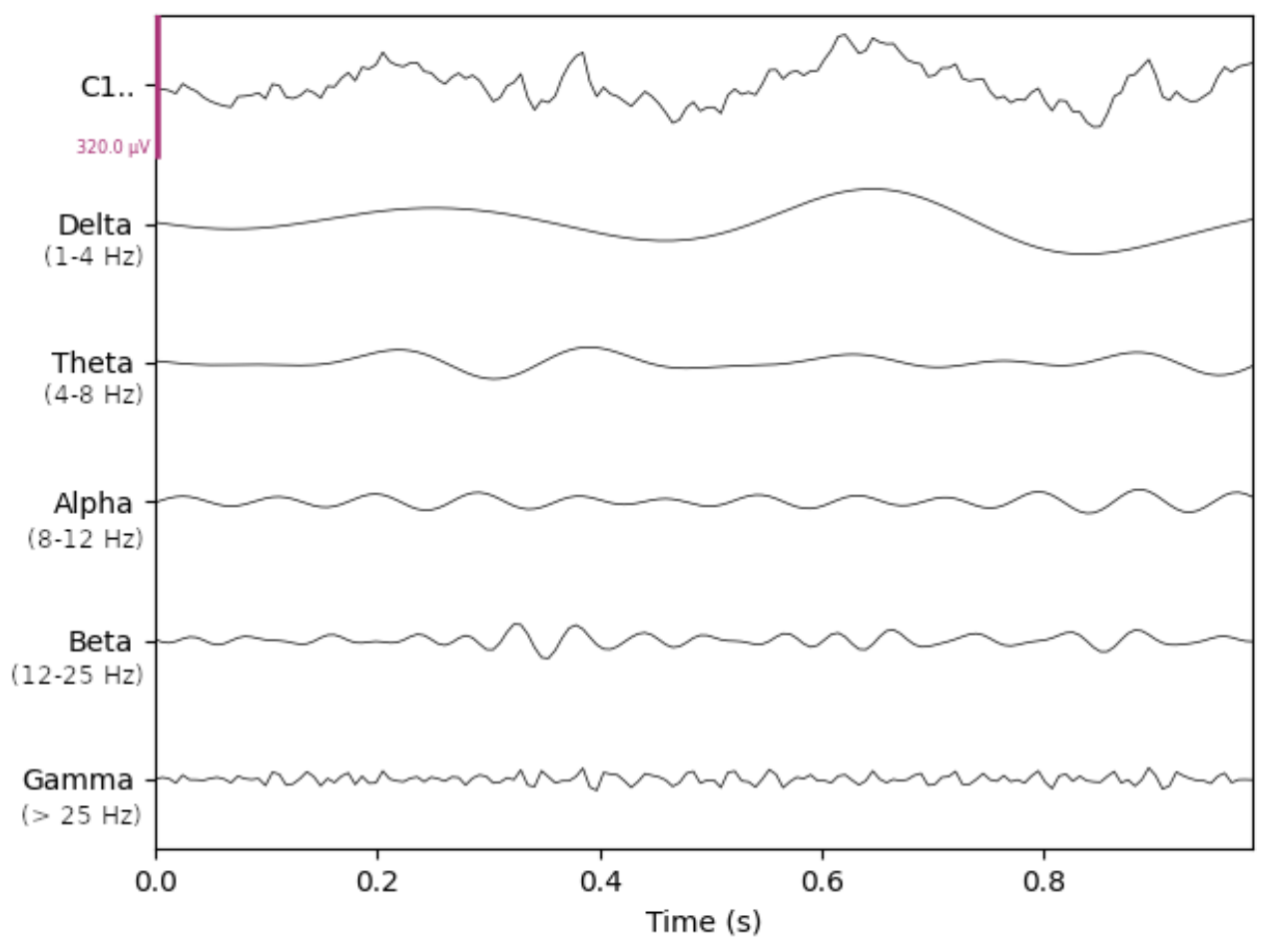

Figure 3. A graphical representation of the different EEG bands generated by filtering the original data (C1..) to obtain the components of $\mathrm{C} 1$.. contained in each frequency band [18]. High frequencies appear to oscillate quickly, while low frequencies oscillate slowly.

Event-related potentials (ERP) are neuroelectrical activities elicited by a sensory, cognitive, or motor stimulus. Waveform analysis, which analyzes the time-domain EEG data immediately following the ERP stimulus, is common for the interpretation of ERP data [18]. Typically, a grand average ERP waveform is created by aligning the waveforms of a group of participants, and is compared to another group of interest. ERP components are specific parts of these waveforms that may be useful in diagnosing disorders in information processing. For example, the P50 ERP component is a positive wave occurring $40-70 \mathrm{~ms}$ after auditory stimulus presentation [23].

\section{$\underline{\text { Aim }}$}

The aim of this literature review is to provide a summary of the fundings in the literature in both resting-state EEG and ERPs in differentiating MCI from AD and healthy aging.

\section{Methods}

Database searches were conducted in PubMed over the period of Feb 23rd, 2021 to March 19th, 2021, the following searches were conducted (all: filtered with full text): "mild cognitive impairment AND Alzheimer's AND (electroencephalogr* OR EEG) AND (detection or diagnosis) AND (resting-state OR (resting state))", and "mild cognitive impairment AND Alzheimer's (electroencephalogr* OR EEG) AND (detection or diagnosis) AND (ERP OR event-related potential)".

Research papers were included if the primary focus was on the use of EEG to distinguish between individuals with MCI and individuals with AD, and between individuals with MCI and healthy controls (HC). As well, papers were required to use ERPs or resting-state EEG data. Primary, peer-reviewed research was included, however reviews/meta-analyses, abstracts, and conference proceedings were excluded.

\section{Results}

Search results

Searches of PubMed yielded 100 records on restingstate, and 125 results on event-related potentials. Following title-abstract screening, 62 papers on resting-state were removed, 73 on event-related potential. The remaining records underwent full-text screening. Fourteen papers were relevant for the resting-state portion of this review, and twenty-eight were relevant for the event-related potential section of this review.

\section{$\underline{\text { Resting-state }}$}

Power spectral density is a common biomarker used in the algorithmic classification of MCI versus healthy controls (HCs). The most common pattern of results reports EEG slowing in MCI compared with healthy aging in middle-high 
frequencies, typically characterized by a reduction in spectral power in the alpha band [25-31]. Furthermore, increases in delta and theta power have also been reported [28,32-35]. As a typical example, Babiloni et al. [30] statistically tested for differences in the power spectra in a matched group of individuals with MCI and healthy controls, finding an overall decrease in posterior brain alpha power in MCI and increase in parietal delta power in MCI relative to controls. Classification of HC versus MCI yielded the highest accuracy when using a ratio of delta to alpha power in this study. This is indicative of a slowing of cognition, as an increase in this ratio indicates increased power in the delta frequency band (containing low frequencies) and decreased power in the alpha frequency band (containing middle-high frequencies). Another common finding in MCI vs HC classification studies is an overall reduction in EEG signal complexity in MCI, as measured by approaches which aim to categorize the predictability of EEG time-domain signals [36-38]. Figure 4 illustrates the idea of signal complexity in more detail.

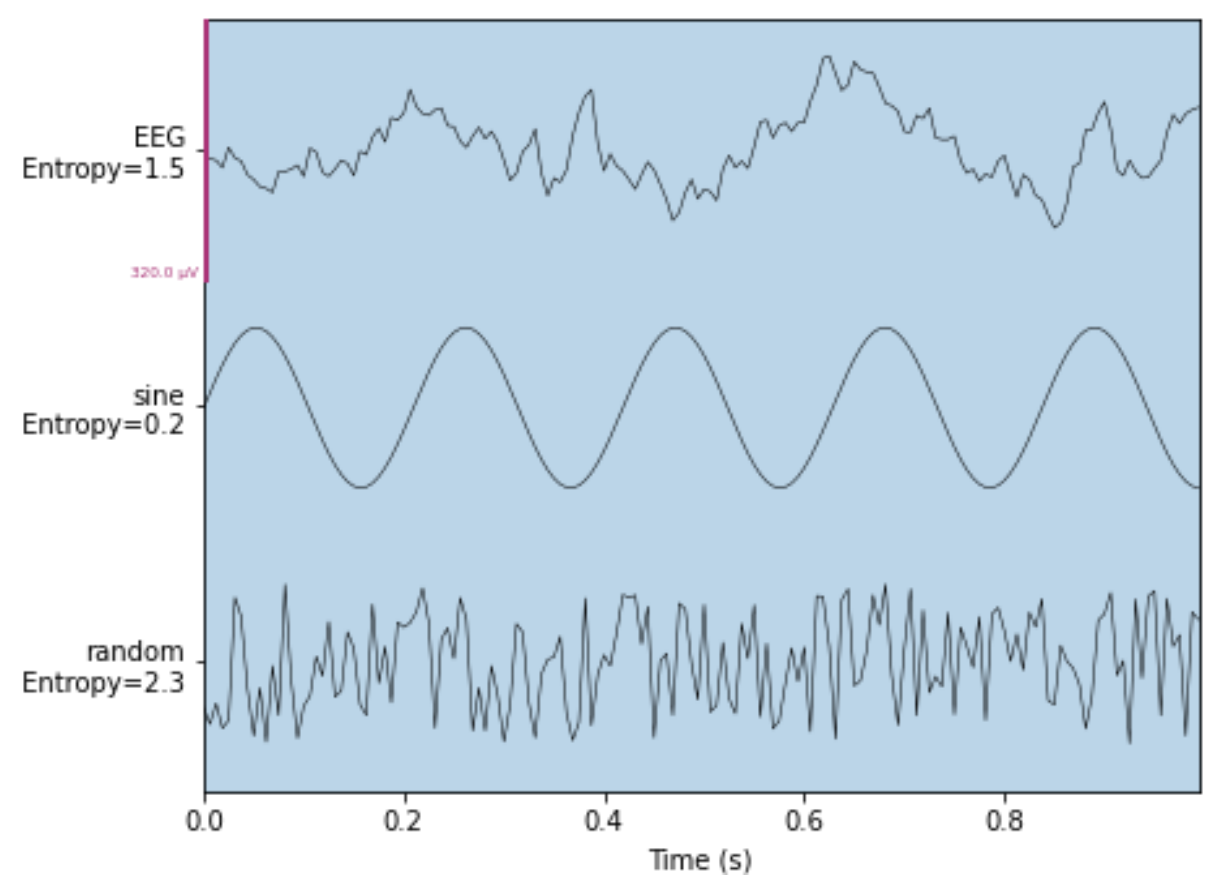

Figure 4. A graphical representation of the concept of signal complexity. Sample entropy is a measure of signal complexity that has been previously used for Alzheimer's disease classification using EEG [38]. This sine wave (perfectly predictable) has a sample entropy of 0.2 , while a uniform random signal (completely unpredictable) has a sample entropy of 2.3 . EEG has a timeseries complexity between the sine wave and the random signal, with a sample entropy of 1.5.

Functional connectivity, the temporal relationship between EEG activity between brain regions, also appears to differ between individuals with MCI and HCs. While connectivity analyses vary, models based on synchronization are commonly used to determine the functional distance between pairs of brain regions [40-43]. Two regions with a high degree of functional connectivity to another may have highly correlated activity, or may have the present activity in one region correlated to the past activity of the other [40-43]. Estimated connectivity strengths between different brain regions can be analyzed using methods based on graph theory, which models distinct points and the connections between them. One such metric relevant to MCI is the global average functional activity, which Franciotti et al. found to be decreased in MCI compared to HC [39]. Another such metric which was reduced in MCI was the small world metric, which identifies how similar a functional network is to a "small-world" network, a common model for neuronal connectivity patterns. In this type of network, most nodes are not directly interconnected, but can be reached through connections to a small number of in-between nodes [40].

\section{Event-Related Potential}

Among ERPs, changes in the P3 (otherwise known as P300) wave is among the most well-researched indicators for MCI and AD. Multiple studies have shown decreased P3 amplitude as well as increased latency in individuals with MCI as compared to controls. Similar findings were made when comparing individuals with MCI who progressed to $\mathrm{AD}$ and MCI-stable participants [45-62]. Included studies examined ERP findings across a variety of tasks, including auditory oddball paradigms, visual congruency and memory tasks (including Simon tasks and N-back tasks), and visual Go-NoGo tasks (both individual and coupled with auditory 
UNDERGRADUATE RESEARCH IN NATURAL AND CLINICAL SCIENCE AND TECHNOLOGY (URNCST) JOURNAL
Read more URNCST Journal articles and submit your own today at: $\underline{\text { https://www.urncst.com }}$

oddball paradigms). An oddball paradigm is a task where participants are presented with repetitive stimuli that is infrequently interrupted by a deviant stimulus. The reaction of the participant to the deviant stimulus, known as the "odd ball", is then recorded [63]. Auditory oddball tasks result in a P300 ERP when shown a deviant stimulus, as shown in the top image in Figure 5. A Simon task is a task where participants are presented with visual stimuli and response features. It is used to measure a participant's ability to respond accurately and within a timely manner depending on the experimental conditions (e.g., stimulus and response are located on the same side of the participant's body) [64]. N- back tasks are continuous recognition measures. During these tasks, participants are presented a sequence of stimuli, such as images. They are then asked to judge if the item in the sequence matched the one presented $\mathbf{N}$ items ago [65]. Finally, a Go-NoGo task measures a participant's impulsiveness. In this task, participants are tasked to respond to certain stimuli (the "go" stimuli") but also instructed to not respond to other stimuli (the "no-go" stimuli). The main measure in this task is the commission error rate, which is the rate of making a "go" response during a "no-go" trial [66].
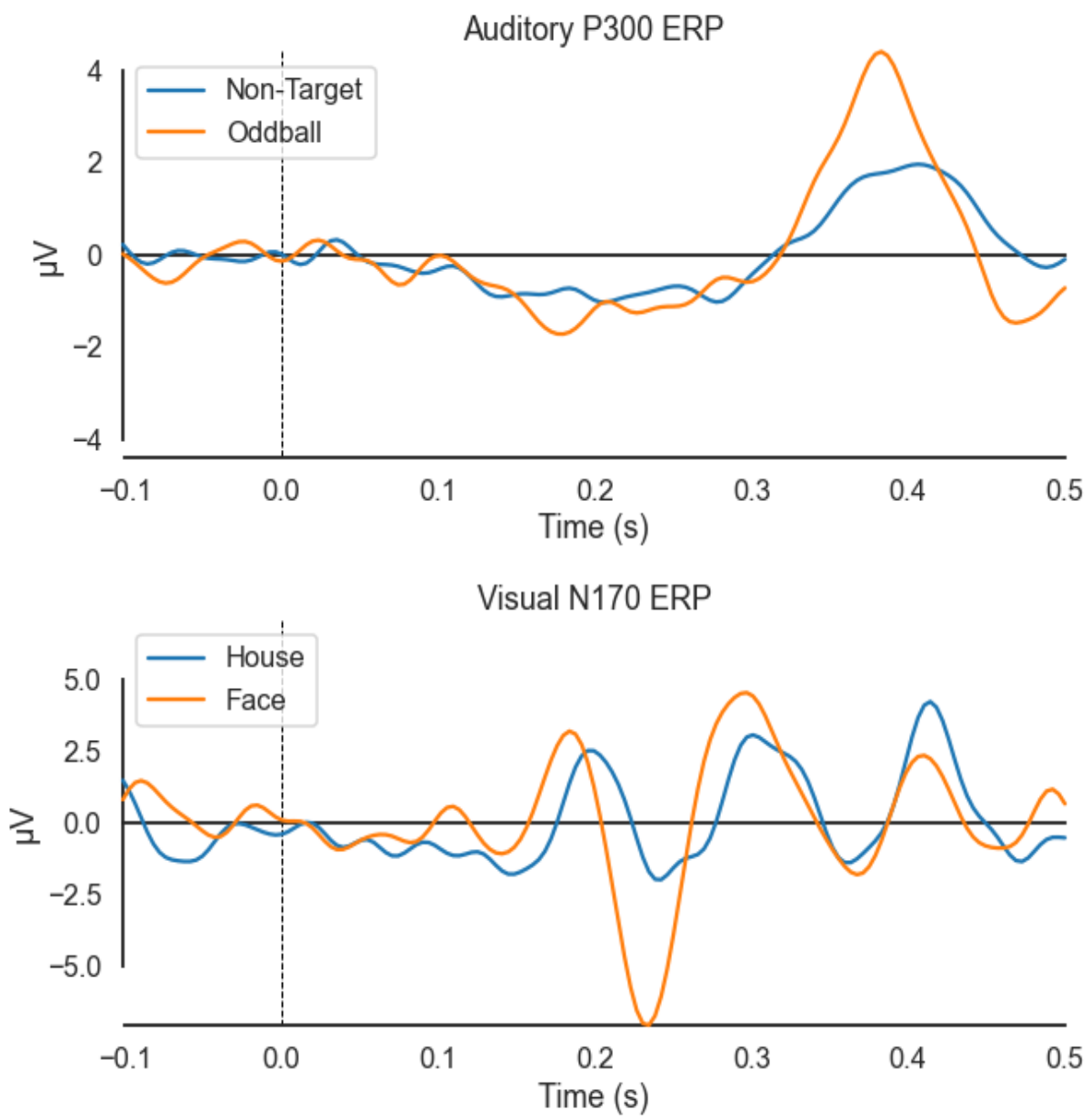

Figure 5. A visualization of representative ERP waveforms obtained from the NeuroTechX/EEG-notebooks ERP datasets [67]. The auditory P300 is a positive waveform (becomes more positive), starting at around $0.3 \mathrm{~s} \mathrm{(300} \mathrm{ms).} \mathrm{It} \mathrm{occurs} \mathrm{when} \mathrm{infrequent}$ (oddball) sounds are shown during an auditory oddball task. The visual N170 is a negative waveform (becomes more negative) starting at around $0.17 \mathrm{~s}(170 \mathrm{~ms})$. This is strongly associated with the perception of faces, rather than other images.

These findings remained relatively consistent across studies despite varying methodologies [45-62]. In particular, Bennys et al. found prolonged P3 latency in an auditory oddball tasks was shown to possess an $87 \%$ to $95 \%$ sensitivity and specificity respectively when discriminating individuals with $\mathrm{AD}$ patients from those with MCI or controls, with the values dropping to $75 \%$ sensitivity and $80 \%$ specificity when discriminating MCI from controls [47]. Overall, P3 waveform readings from cognitive ERPs provide a reliable and useful tool in the prediction of the development of MCI or its progressive decline into AD. 
UNDERGRADUATE RESEARCH IN NATURAL AND CLINICAL SCIENCE AND TECHNOLOGY (URNCST) JOURNAL Read more URNCST Journal articles and submit your own today at: https://www.urncst.com

Extended latency has also been identified in the N2 (or N200) wave in individuals with MCI. In particular, individuals with amnestic MCI (aMCI), defined as individuals with a measurable decline in cognitive memory abilities and at risk for Alzheimer's, have shown significantly delayed $\mathrm{N} 2$ waves in visual Go/NoGo tasks compared to controls [51,52]. This difference was also found to be more pronounced in healthy older adults, suggesting an agerelated effect on $\mathrm{N} 2$ differences [68]. Compared to the P3, the $\mathrm{N} 2$ possessed greater discriminatory capability when assessing individuals with MCI and controls, with a $90 \%$ sensitivity and 70\% specificity [58]. N2 amplitudes, by contrast, have shown mixed responses in individuals with MCI. Studies by Cid-Fernández et al. and Cespón et al. found decreased $\mathrm{N} 2$ amplitudes in certain the aMCI group compared to controls [46,70]. However, in response to auditory ERPs, Papaliagkas et al. found individuals with MCI to possess significantly higher N2 amplitudes than controls [59]. Regardless of the evidence regarding N2 amplitude, N2 latency may still be utilised effectively alongside P3 amplitude and latency as a strong marker for the detection and monitoring of progression of MCI.

In comparison, other waveforms are less well-studied. The N170 waveform is a negative waveform that is elicited when faces are shown to subjects, as shown in the bottom image in Figure 5. The sensory N170 amplitudes elicited from visual stimuli have been shown to be significantly increased in individuals with AD and MCI when shown faces expressing "Anger" or "Fear" compared to controls [71]. N170 latency was also separately demonstrated to be prolonged in individuals with $\mathrm{AD}$ compared to $\mathrm{MCI}$ or controls [71-73]. P1 and N1 waveforms, in contrast, have shown decreased amplitudes in individuals with MCI compared to controls [53,56,58,73-76]. The overall lack of evidence on early sensory ERP waves implies less certainty on their diagnostic effectiveness when discriminating between MCI, AD, and healthy aging. However, these waves may point to future avenues of research, and may nonetheless be used to support observations gathered from other ERP waves.

\section{Discussion}

The main results in resting-state EEG include a slowing of spectral power, a reduction in EEG signal complexity, and a number of differences in functional connectivity. Restingstate EEG studies highlight several distinct differences between individuals with MCI and healthy controls, including a possible reduction in the power of oscillatory brain activity in MCI. Additionally, the literature suggests that $\mathrm{MCI}$ is associated with a general functional disconnection between brain regions, further suggesting AD as a disease of disconnectivity. A majority of the studies attempt to create automatic classifiers differentiating MCI from healthy aging using spectral, functional connectivity, or signal complexity measures. This indicates a high level of coherence in the literature with regards to the general types of resting-state EEG features that may be useful in differentiating MCI from healthy aging.

ERPs may also be utilized to discriminate between individuals with $\mathrm{MCI}$ and those with $\mathrm{AD}$, in addition to serving as a marker of cognitive decline along the MCI-AD spectrum of cognitive disorders. Decreased amplitude of the P3 wave, along with increased latency of the P3 and N2 waves, demonstrate good sensitivity and specificity to warrant further investigation as potential markers of MCI or AD. Changes in $\mathrm{N} 2$ amplitude may also provide a useful indicator of MCI, however, whether N2 amplitude increases or decreases appears to depend on the sensory modality under examination by the task. More research into the ERP differences between auditory and non-auditory tasks is warranted before consideration of using N2 amplitude as an indicator. Furthermore, some studies have revealed an effect of age on the differences observed in ERP waves between $\mathrm{AD}, \mathrm{MCI}$, and healthy aging. It remains unclear whether this is a consequence of the greater risk of $\mathrm{AD}$ and $\mathrm{MCI}$ in older age, or a potential marker identifying at-risk older individuals. Regardless, ERP waveforms hold great potential as tools to assist in the prediction or diagnosis of MCI and AD.

The literature supports a wide variety of different measures using EEG in the diagnosis of MCI. Firstly, the choice of resting-state versus ERP-based experiments must be considered. Within resting-state experiments, a number of different biomarkers may be analyzed (e.g., frequency band power, complexity measures and functional connectivity measures). Using ERP data, the latency and amplitude of a number of different ERP waveforms may be analyzed instead.

While literature does share a number of common findings, there does not yet exist a universally accepted best practice for MCI classification using EEG data. This may necessitate the collaboration between clinicians and experts in EEG to facilitate effective use of EEG in clinical settings [76]. Therefore, further research is needed to clarify effective AD-MCI biomarkers and to make the literature accessible to clinicians.

\section{Conclusions}

In summary, MCI is associated with subtle but distinct changes in cognition that can be detected by both restingstate EEG data and ERPs. This review has found that both resting-state EEG and ERP findings indicate a general slowing of components that relate to cognitive function, with resting-state studies showing a slowing of the power spectrum, and ERP studies indicating a greater latency in ERP components. EEG holds great promise as a clinical tool to improve $\mathrm{AD}$ and $\mathrm{MCI}$ diagnosis and monitoring the efficacy of treatment. Further research may be required to standardize protocols for acquiring existing resting-state EEG biomarkers, and to clarify the roles of P100 and N100 in ERP studies. Additionally, more research is needed to apply these findings in a clinical setting. 
UNDERGRADUATE RESEARCH IN NATURAL AND CLINICAL SCIENCE AND TECHNOLOGY (URNCST) JOURNAL Read more URNCST Journal articles and submit your own today at: https://www.urncst.com

\author{
List of Abbreviations Used \\ AD: Alzheimer's disease \\ EEG: electroencephalography \\ ERP: event-related potentials \\ FFT: fast Fourier transform \\ MCI: mild cognitive impairment \\ NINCDS-ADRDA: National Institute of Neurological and \\ Communicative Disorders and Stroke-Alzheimer's Disease \\ and Related Disorders Association
}

\section{Conflicts of Interest}

The authors declare that they have no conflicts of interest.

\section{Ethics Approval and/or Participant Consent}

This study was a literature review and did not require ethics approval.

\section{Authors' Contributions}

MCS: made contributions to the search strategy, performed title/abstract review and full-text review, drafted the manuscript, and gave final approval of the version to be published.

ZA: made contributions to the search strategy, performed title/abstract review and full-text review, drafted the manuscript, and gave final approval of the version to be published.

JHD: made contributions to the search strategy, performed title/abstract review and full-text review, drafted the manuscript, and gave final approval of the version to be published.

\section{Acknowledgements}

Ricky Chow was a mentor for the URNCST Mentored Paper Initiative and assisted with the editing of this paper. The authors thank the developers of NeurotechX/eeg-notebooks, MNE-Python, and BCI2000 for making their datasets and/or code available on a free and open-source basis.

\section{Funding}

This study was not funded.

\section{References}

[1] Weller J, Budson A. Current understanding of Alzheimer's disease diagnosis and treatment. F1000Research. 2018;7:1161. https://doi.org/10.12688/ f1000research.14506.1

[2] Soria Lopez J, González H, Léger G. Alzheimer's disease. Handbook of Clinical Neurology. 2019; 231-255. https://doi.org/10.1016/b978-0-12-804766$\underline{\text { 8.00013-3 }}$

[3] Kelley BJ, Petersen RC. Alzheimer's disease and mild cognitive impairment. Neurologic Clinics. 2007 Aug;25(3):577-v. https://doi.org/10.1016/j.ncl.2007 .03 .008
[4] Varatharajah Y, Ramanan VK, Iyer R, Vemuri P. Predicting short-term MCI-to-AD progression using imaging, CSF, genetic factors, cognitive resilience, and demographics. Scientific Reports. 2019 Feb 19;9(1):2235. https://doi.org/10.1038/s41598-01938793-3

[5] Belleville S, Fouquet C, Hudon C, Zomahoun HTV, Croteau J, Consortium for the early identification of Alzheimer's disease-Quebec. Neuropsychological measures that predict progression from mild cognitive impairment to Alzheimer's type dementia in older adults: A systematic review and meta-analysis. Neuropsychology Review. 2017 Dec 1;27(4):328-53. https://doi.org/10.1007/s11065-017-9361-5

[6] McKhann GM, Knopman DS, Chertkow H, Hyman BT, Jack CR, Kawas CH, et al. The diagnosis of dementia due to Alzheimer's disease:

Recommendations from the national institute on agingAlzheimer's association workgroups on diagnostic guidelines for Alzheimer's disease. Alzheimer's \& Dementia. 2011 May;7(3):263-9. https://doi.org/ 10.1016/j.jalz.2011.03.005

[7] Vakil E. Neuropsychological assessment: Principles, rationale, and challenges. Journal of Clinical and Experimental Neuropsychology. 2012 Feb 1;34(2):135-50. https://doi.org/10.1080/13803395 .2011 .623121

[8] Schroeder RW, Martin PK, Walling A. Neuropsychological evaluations in adults. American Family Physician. 2019 Jan 15;99(2):101-8.

[9] Neuropsychological evaluation FAQ [Internet]. Department of Neurology. [cited 2021 Apr 9]. Available from: https://www.med.unc.edu/neurology/ divisions/movement-disorders/npsycheval/

[10] Miskin C, Carvalho KS, Valencia I, Legido A, Khurana DS. EEG duration: The long and the short of it. Journal of Child Neurology. 2015 Nov;30(13):17679. https://doi.org/10.1177/0883073815579969

[11] Joanne G. Neuropsychological evaluation of the older adult. Elsevier; 2000.

[12] Hubbard J, Kikumoto A, Mayr U. EEG decoding reveals the strength and temporal dynamics of goalrelevant representations. Scientific Reports. 2019 Jun 21;9(1):9051. https://doi.org/10.1038/s41598-01945333-6

[13] Britton JW, Frey LC, Hopp JL, Korb P, Koubeissi MZ, Lievens WE, et al. Electroencephalography (EEG): An introductory text and atlas of normal and abnormal findings in adults, children, and infants [Internet]. St. Louis EK, Frey LC, editors. Chicago: American Epilepsy Society; 2016 [cited 2021 Apr 9]. Available from: http://www.ncbi.nlm.nih.gov/books/NBK390354/

[14] Reducing power line noise in EEG and MEG data via spectrum interpolation. NeuroImage. $2019 \mathrm{Apr}$ 1;189:763-76. https://doi.org/10.1016/j.neuroimage .2019 .01 .026 
UNDERGRADUATE RESEARCH IN NATURAL AND CLINICAL SCIENCE AND TECHNOLOGY (URNCST) JOURNAL Read more URNCST Journal articles and submit your own today at: https://www.urncst.com

[15] Val-Calvo M, Álvarez-Sánchez J, Ferrández-Vicente J, Fernández E. Optimization of real-time EEG artifact removal and emotion estimation for human-robot interaction applications. Frontiers in Computational Neuroscience. 2019;13. https://doi.org/10.3389/fncom .2019 .00080

[16] Ramele R, Villar AJ, Santos JM. EEG waveform analysis of P300 ERP with applications to brain computer interfaces. Brain Sciences. 2018 Nov;8(11):199. https://doi.org/10.3390/brainsci8110 199

[17] EEG (electroencephalography): The complete pocket guide - iMotions [Internet]. Imotions Publish. 2019 [cited 2021 Apr 9]. Available from: https://imotions.com/blog/eeg/

[18] Banz BC, Yip SW, Yau YHC, Potenza MN. Behavioral addictions in addiction medicine: From mechanisms to practical considerations. Progress in Brain Research. 2016;223:311-28. https://doi.org/10 $.1016 / \mathrm{bs}$. pbr.2015.08.003

[19] Rogala J, Kublik E, Krauz R, Wróbel A. Resting-state EEG activity predicts frontoparietal network reconfiguration and improved attentional performance. Scientific Reports. 2020;10(1). https://doi.org/10.1038/ s41598-020-61866-7

[20] Schalk G, McFarland DJ, Hinterberger T, Birbaumer N, Wolpaw JR. BCI2000: A general-purpose braincomputer interface (BCI) system. IEEE Transactions on Biomedical Engineering. 2004 Jun;51(6):1034-43. https://doi.org/10.1109/TBME.2004.827072

[21] Gramfort A, Luessi M, Larson E, Engemann DA, Strohmeier D, Brodbeck C, et al. MEG and EEG data analysis with MNE-Python. Frontiers in Neuroscience. 2013;7. https://doi.org/10.3389/fnins.2013.00267

[22] Delorme A, Miyakoshi M, Jung T-P, Makeig S. Grand average ERP-image plotting and statistics: A method for comparing variability in event-related single-trial EEG activities across subjects and conditions. Journal of Neuroscience Methods. 2015 Jul 30;250:3-6. https://doi.org/10.1016/j.jneumeth.2014.10.003

[23] Thomas C, vom Berg I, Rupp A, Seidl U, Schröder J, Roesch-Ely D, et al. P50 gating deficit in Alzheimer dementia correlates to frontal neuropsychological function. Neurobiology of Aging. 2010 Mar 1;31(3):416-24. https://doi.org/10.1016/j.neurobiolaging .2008 .05 .002

[24] Banz BC, Yip SW, Yau YHC, Potenza MN. Behavioral addictions in addiction medicine: From mechanisms to practical considerations. Progress in Brain Research. 2016;223:311-28. https://doi.org/ 10.1016/bs.pbr.2015.08.003

So et al. | URNCST Journal (2021): Volume 5, Issue 8

DOI Link: https://doi.org/10.26685/urncst.272
[25] Mazzon G, De Dea F, Cattaruzza T, Manganotti P, Monti F, Accardo A. Memorization test and resting state EEG components in mild and subjective cognitive impairment. Current Alzheimer Research.

2018;15(9):809-19. https://doi.org/10.2174/156720501 $\underline{5666180427114520}$

[26] Babiloni C, Del Percio C, Pascarelli MT, Lizio R, Noce G, Lopez S, et al. Abnormalities of functional cortical source connectivity of resting-state electroencephalographic alpha rhythms are similar in patients with mild cognitive impairment due to Alzheimer's and Lewy body diseases. Neurobiology of Aging. 2019 May;77:112-27. https://doi.org/10.1016/ j.neurobiolaging.2019.01.013

[27] Núñez P, Poza J, Gómez C, Rodríguez-González V, Hillebrand A, Tola-Arribas MA, et al. Characterizing the fluctuations of dynamic resting-state electrophysiological functional connectivity: Reduced neuronal coupling variability in mild cognitive impairment and dementia due to Alzheimer's disease. Journal of Neural Engineering. 2019 Sep 17;16(5):056030. https://doi.org/10.1088/1741-2552/ ab234b

[28] Jovicich J, Babiloni C, Ferrari C, Marizzoni M, Moretti DV, Del Percio C, et al. Two-year longitudinal monitoring of amnestic mild cognitive impairment patients with prodromal Alzheimer's disease using topographical biomarkers derived from functional magnetic resonance imaging and electroencephalographic activity. Journal of Alzheimer's Disease. 2019;69(1):15-35. https://doi.org/ 10.3233/JAD-180158

[29] Lizio R, Babiloni C, Del Percio C, Losurdo A, Vernò L, De Tommaso M, et al. Different abnormalities of cortical neural synchronization mechanisms in patients with mild cognitive impairment due to Alzheimer's and chronic kidney diseases: An EEG study. Journal of Alzheimer's Disease. 2018;65(3):897-915. https://doi.org/10.3233/JAD-180245

[30] Babiloni C, Del Percio C, Lizio R, Noce G, Lopez S, Soricelli A, et al. Abnormalities of resting state cortical EEG rhythms in subjects with mild cognitive impairment due to Alzheimer's and Lewy body diseases. Journal of Alzheimer's Disease. 2018;62(1):247-68. https://doi.org/10.3233/JAD170703

[31] Gouw AA, Alsema AM, Tijms BM, Borta A, Scheltens P, Stam CJ, et al. EEG spectral analysis as a putative early prognostic biomarker in nondemented, amyloid positive subjects. Neurobiology of Aging. 2017 Sep;57:133-42. https://doi.org/10.1016/j.neurobio laging.2017.05.017 
UNDERGRADUATE RESEARCH IN NATURAL AND CLINICAL SCIENCE AND TECHNOLOGY (URNCST) JOURNAL Read more URNCST Journal articles and submit your own today at: https://www.urncst.com

[32] Babiloni C, Noce G, Di Bonaventura C, Lizio R, Pascarelli M, Tucci F et al. Abnormalities of cortical sources of resting state delta electroencephalographic rhythms are related to epileptiform activity in patients with amnesic mild cognitive impairment not due to Alzheimer's disease. Frontiers in Neurology. 2020;11. https://doi.org/10.3389/fneur.2020.514136

[33] Babiloni C, Del Percio C, Lizio R, Noce G, Cordone S, Lopez S et al. Abnormalities of cortical neural synchronization mechanisms in subjects with mild cognitive impairment due to Alzheimer's and Parkinson's diseases: An EEG study. Journal of Alzheimer's Disease. 2017;59(1):339-358. https://doi.org/10.3233/JAD-160883

[34] Babiloni C, Lizio R, Vecchio F, Frisoni GB, Pievani $\mathrm{M}$, Geroldi C, et al. Reactivity of cortical alpha rhythms to eye opening in mild cognitive impairment and Alzheimer's disease: An EEG study. Journal of Alzheimer's Disease. 2010;22(4):1047-64. https://doi.org/10.3233/JAD-2010-100798

[35] Babiloni C, Carducci F, Lizio R, Vecchio F, Baglieri A, Bernardini S, et al. Resting state cortical electroencephalographic rhythms are related to gray matter volume in subjects with mild cognitive impairment and Alzheimer's disease. Human Brain Mapping. 2013 Jun;34(6):1427-46. https://doi.org/ $10.1002 / \mathrm{hbm} .22005$

[36] Mazzon G, De Dea F, Cattaruzza T, Manganotti P, Monti F, Accardo A. Memorization test and resting state EEG components in mild and subjective cognitive impairment. Current Alzheimer Research. 2018;15(9):809-19. https://doi.org/10.2174/156720501 $\underline{5666180427114520}$

[37] McBride JC, Zhao X, Munro NB, Smith CD, Jicha GA, Hively L, et al. Spectral and complexity analysis of scalp EEG characteristics for mild cognitive impairment and early Alzheimer's disease. Computer Methods and Programs in Biomedicine. 2014 Apr;114(2):153-63. https://doi.org/10.1016/j.cmpb. 2014.01.019

[38] Simons S, Abasolo D, Escudero J. Classification of Alzheimer's disease from quadratic sample entropy of electroencephalogram. Healthcare Technology Letters. 2015 May 21;2(3):70-3. https://doi.org/10.1049/ htl.2014.0106

[39] Timothy LT, Krishna BM, Nair U. Classification of mild cognitive impairment EEG using combined recurrence and cross recurrence quantification analysis. International Journal of Psychophysiology. 2017 Oct;120:86-95. https://doi.org/10.1016/j.ijpsycho.2017 .07 .006

[40] Yu S, Huang D, Singer W, Nikolić D. A small world of neuronal synchrony. Cerebral Cortex. 2008 Dec;18(12):2891-901. https://doi.org/10.1093/cercor $\underline{\text { bhn047 }}$

So et al. | URNCST Journal (2021): Volume 5, Issue 8 DOI Link: https://doi.org/10.26685/urncst.272
[41] Miraglia F, Vecchio F, Bramanti P, Rossini PM. EEG characteristics in "eyes-open" versus "eyes-closed" conditions: Small-world network architecture in healthy aging and age-related brain degeneration. Clinical Neurophysiology. 2016 Feb;127(2):1261-8. https://doi.org/10.1016/j.clinph.2015.07.040

[42] Frantzidis C, Vivas A, Tsolaki A, Klados M, Tsolaki M, Bamidis P. Functional disorganization of smallworld brain networks in mild Alzheimer's Disease and amnestic mild cognitive impairment: An EEG study using Relative Wavelet Entropy (RWE). Frontiers in Aging Neuroscience. 2014;6. https://doi.org/10.3389/ fnagi.2014.00224

[43] Franciotti R, Falasca NW, Arnaldi D, Famà F, Babiloni $\mathrm{C}$, Onofrj $\mathrm{M}$, et al. Cortical network topology in prodromal and mild dementia due to Alzheimer's disease: Graph theory applied to resting state EEG. Brain Topography. 2019 Jan;32(1):127-41. https://doi.org/10.1007/s10548-018-0674-3

[44] Požar R, Giordani B, Kavcic V. Effective differentiation of mild cognitive impairment by functional brain graph analysis and computerized testing. PLOS ONE. 2020 Mar 16;15(3):e0230099. https://doi.org/10.1371/journal.pone.0230099

[45] Jervis BW, Bigan C, Jervis MW, Besleaga M. Newonset Alzheimer's disease and normal subjects $100 \%$ differentiated by P300. American Journal of Alzheimer's Disease \& Other Dementias. 2019 Aug 1;34(5):308-13. https://doi.org/10.1177/15333175 19828101

[46] Cespón J, Galdo-Álvarez S, Pereiro AX, Díaz F. Differences between mild cognitive impairment subtypes as indicated by event-related potential correlates of cognitive and motor processes in a Simon task. Journal of Alzheimer's Disease. 2015;43(2): 631-47. https://doi.org/10.3233/JAD-132774

[47] Bennys K, Portet F, Touchon J, Rondouin G. Diagnostic value of event-related evoked potentials N200 and P300 subcomponents in early diagnosis of Alzheimer's disease and mild cognitive impairment. Journal of Clinical Neurophysiology. 2007 Oct;24(5):405-12. https://doi.org/10.1097/WNP.0b013 e31815068d5

[48] Li J, Broster LS, Jicha GA, Munro NB, Schmitt FA, Abner E, et al. A cognitive electrophysiological signature differentiates amnestic mild cognitive impairment from normal aging. Alzheimer's Research \& Therapy. 2017 Jan 19;9(1):3. https://doi.org/ 10.1186/s13195-016-0229-3

[49] Chiang H-S, Spence JS, Kraut MA, Mudar RA. Age effects on event-related potentials in individuals with amnestic mild cognitive impairment during semantic categorization Go/NoGo tasks. Neuroscience Letters. 2018 Mar 23;670:19-21. https://doi.org/10.1016/ j.neulet.2018.01.034 
UNDERGRADUATE RESEARCH IN NATURAL AND CLINICAL SCIENCE AND TECHNOLOGY (URNCST) JOURNAL Read more URNCST Journal articles and submit your own today at: https://www.urncst.com

[50] Tsolaki AC, Kosmidou V, Kompatsiaris IY, Papadaniil C, Hadjileontiadis L, Adam A, et al. Brain source localization of MMN and P300 ERPs in mild cognitive impairment and Alzheimer's disease: A high-density EEG approach. Neurobiology of Aging. 2017 Jul;55:190-201. https://doi.org/10.1016/j.neurobio laging.2017.03.025

[51] Mudar RA, Chiang H-S, Eroh J, Nguyen LT, Maguire MJ, Spence JS, et al. The effects of amnestic mild cognitive impairment on go/no go semantic categorization task performance and event-related potentials. Journal of Alzheimer's Disease. 2016;50(2):577-90. https://doi.org/10.3233/JAD$\underline{150586}$

[52] Csukly G, Sirály E, Fodor Z, Horváth A, Salacz P, Hidasi $Z$ et al. The differentiation of amnestic type MCI from the non-amnestic types by structural MRI. Frontiers in Aging Neuroscience. 2016;8. https://doi.org/10.3389/fnagi.2016.00052

[53] Gu L-H, Chen J, Gao L-J, Shu H, Wang Z, Liu D, et al. The effect of apolipoprotein e $\varepsilon 4$ (apoe $\varepsilon 4$ ) on visuospatial working memory in healthy elderly and amnestic mild cognitive impairment patients: An event-related potentials study. Frontiers in Aging Neuroscience. 2017;9:145. https://doi.org/10.3389/ fnagi.2017.00145

[54] Cid-Fernández S, Lindín M, Díaz F. Effects of amnestic mild cognitive impairment on $\mathrm{N} 2$ and $\mathrm{P} 3$ Go/NoGo ERP components. Journal of Alzheimer's Disease. 2014;38(2):295-306. https://doi.org/10.3233/ JAD-130677

[55] Wang P, Zhang X, Liu Y, Liu S, Zhou B, Zhang Z, et al. Perceptual and response interference in Alzheimer's disease and mild cognitive impairment. Clinical Neurophysiology. 2013 Dec;124(12):2389-96. https://doi.org/10.1016/j.clinph.2013.05.014

[56] Julkunen P, Jauhiainen AM, Westerén-Punnonen S, Pirinen E, Soininen H, Könönen M, et al. Navigated TMS combined with EEG in mild cognitive impairment and Alzheimer's disease: A pilot study. Journal of Neuroscience Methods. 2008 Jul 30;172(2):270-6. https://doi.org/10.1016/j.jneumeth .2008 .04 .021

[57] Olichney JM, Yang J-C, Taylor J, Kutas M. Cognitive event-related potentials: Biomarkers of synaptic dysfunction across the stages of Alzheimer's disease. Journal of Alzheimer's Disease. 2011;26 Suppl 3:21528. https://doi.org/10.3233/JAD-2011-0047

[58] Lai C-L, Lin R-T, Liou L-M, Liu C-K. The role of event-related potentials in cognitive decline in Alzheimer's disease. Clinical Neurophysiology. 2010 Feb;121(2):194-9. https://doi.org/10.1016/j.clinph $\underline{.2009 .11 .001}$

So et al. | URNCST Journal (2021): Volume 5, Issue 8 DOI Link: https://doi.org/10.26685/urncst.272
[59] Papaliagkas V, Kimiskidis V, Tsolaki M, Anogianakis G. Usefulness of event-related potentials in the assessment of mild cognitive impairment. BMC Neuroscience. 2008 Nov 5;9(1):107. https://doi.org/ 10.1186/1471-2202-9-107

[60] Papaliagkas VT, Anogianakis G, Tsolaki MN, Koliakos G, Kimiskidis VK. Combination of P300 and CSF $\beta$-amyloid(1-42) assays may provide a potential tool in the early diagnosis of Alzheimer's disease. Current Alzheimer Research. 2010 Jun;7(4):295-9. https://doi.org/10.2174/156720510791162421

[61] van Deursen JA, Vuurman EFPM, Smits LL, Verhey FRJ, Riedel WJ. Response speed, contingent negative variation and P300 in Alzheimer's disease and MCI. Brain and Cognition. 2009 Apr;69(3):592-9. https://doi.org/10.1016/j.bandc.2008.12.007

[62] Newsome RN, Pun C, Smith VM, Ferber S, Barense MD. Neural correlates of cognitive decline in older adults at-risk for developing MCI: Evidence from the CDA and P300. Cognitive Neuroscience. 2013;4(34):152-62. https://doi.org/10.1080/17588928.2013 .853658

[63] López Zunini RA, Knoefel F, Lord C, Breau M, Sweet L, Goubran R, et al. P300 amplitude alterations during inhibitory control in persons with mild cognitive impairment. Brain Research. 2016 Sep 1;1646:241-8. https://doi.org/10.1016/j.brainres.2016.06.005

[64] Huettel SA, McCarthy G. What is odd in the oddball task? Prefrontal cortex is activated by dynamic changes in response strategy. Neuropsychologia. 2004;42(3):379-86. https://doi.org/10.1016/j.neurop sychologia.2003.07.009

[65] Salzer Y, Aisenberg D, Oron-Gilad T, Henik A. In touch with the Simon effect. Journal of Experimental Psychology. 2014;61(3):165-79. https://doi.org/10 $.1027 / 1618-3169 / \mathrm{a} 000236$

[66] Coulacoglou C, Saklofske D. Executive function, theory of mind, and adaptive behavior. Psychometrics and Psychological Assessment. 2017;:91-130. https://doi.org/10.1016/b978-0-12-802219-1.00005-5

[67] Barachant A, Banville H, Morrison D, Shapiro B, Griffths J, Easson A et al. NeuroTechX/eeg-notebooks [Internet]. GitHub. 2021 [cited 2 June 2021]. Available from: https://github.com/NeuroTechX/eeg-notebooks

[68] Cespón J, Galdo-Álvarez S, Díaz F. Electrophysiological correlates of amnestic mild cognitive impairment in a Simon task. PLOS ONE. 2013 Dec 5;8(12):e81506. https://doi.org/10.1371/ journal.pone.0081506

[69] Missonnier P, Deiber M-P, Gold G, Herrmann FR, Millet P, Michon A, et al. Working memory loadrelated electroencephalographic parameters can differentiate progressive from stable mild cognitive impairment. Neuroscience. 2007 Dec 5;150(2):346-56. https://doi.org/10.1016/j.neuroscience.2007.09.009

\footnotetext{
DI
} 
UNDERGRADUATE RESEARCH IN NATURAL AND CLINICAL SCIENCE AND TECHNOLOGY (URNCST) JOURNAL Read more URNCST Journal articles and submit your own today at: https://www.urncst.com

[70] Caravaglios G, Castro G, Muscoso EG, Crivelli D, Balconi M. Beta responses in healthy elderly and in patients with amnestic mild cognitive impairment during a task of temporal orientation of attention. Clinical EEG and Neuroscience. 2018 Jul;49(4):25871. https://doi.org/10.1177/1550059416676144

[71] Lazarou I, Adam K, Georgiadis K, Tsolaki A, Nikolopoulos S, Yiannis Kompatsiaris I, et al. Can a novel high-density EEG approach disentangle the differences of visual event related potential (N170), elicited by negative facial stimuli, in people with subjective cognitive impairment? Journal of Alzheimer's Disease. 2018;65(2):543-75. https://doi.org/10.3233/JAD-180223

[72] Saavedra C, Iglesias J, Olivares EI. Event-related potentials elicited by face identity processing in elderly adults with cognitive impairment. Experimental Aging Research. 2012;38(2):220-45. https://doi.org/10.1080/ $\underline{0361073 X .2012 .660057}$
[73] Yamasaki T, Goto Y, Ohyagi Y, Monji A, Munetsuna S, Minohara M, et al. Selective impairment of optic flow perception in amnestic mild cognitive impairment: Evidence from event-related potentials. Journal of Alzheimer's Disease. 2012;28(3):695-708. https://doi.org/10.3233/JAD-2011-110167

[74] Stothart G, Kazanina N, Näätänen R, Haworth J, Tales A. Early visual evoked potentials and mismatch negativity in Alzheimer's disease and mild cognitive impairment. Journal of Alzheimer's Disease. 2015;44(2):397-408. https://doi.org/10.3233/JAD140930

[75] Irimajiri R, Golob EJ, Starr A. Auditory brain-stem, middle- and long-latency evoked potentials in mild cognitive impairment. Clinical Neurophysiology. 2005 Aug;116(8):1918-29. https://doi.org/10.1016/j.clinph .2005 .04 .010

[76] Anderson D, Jirsch JD, Wheatley MB, Brindley PG. Electroencephalogram patterns in critical care: A primer for acute care doctors. Journal of the Intensive Care Society. 2020 Aug 18;1751143720949454. https://doi.org/10.1177/1751143720949454

\section{Article Information}

Managing Editor: Jeremy Y. Ng

Peer Reviewers: Ricky Chow, Bi-ru Amy Yeung

Article Dates: Received Apr 10 21; Accepted Jun 22 21; Published Aug 2521

\section{Citation}

Please cite this article as follows:

So MC, Abdallah Z, Du JH. Examining the use of electroencephalography for the diagnosis of Alzheimer's disease and mild cognitive impairment. URNCST Journal. 2021 Aug 25:5(8). https://urncst.com/index.php/urncst/article/view/272

DOI Link: https://doi.org/10.26685/urncst.272

\section{Copyright}

(C) Matthew Connor So, Zahra Abdallah, Jia Hui Du. (2021). Published first in the Undergraduate Research in Natural and Clinical Science and Technology (URNCST) Journal. This is an open access article distributed under the terms of the Creative Commons Attribution License (https://creativecommons.org/licenses/by/4.0/), which permits unrestricted use, distribution, and reproduction in any medium, provided the original work, first published in the Undergraduate Research in Natural and Clinical Science and Technology (URNCST) Journal, is properly cited. The complete bibliographic information, a link to the original publication on http://www.urncst.com, as well as this copyright and license information must be included.
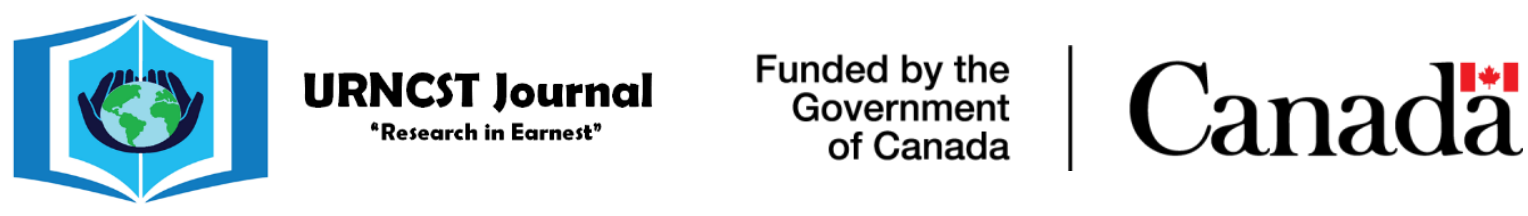

Do you research in earnest? Submit your next undergraduate research article to the URNCST Journal!

| Open Access | Peer-Reviewed | Rapid Turnaround Time | International |

| Broad and Multidisciplinary | Indexed | Innovative | Social Media Promoted |

Pre-submission inquiries? Send us an email at info@ urncst.com | Facebook, Twitter and LinkedIn: @URNCST

Submit YOUR manuscript today at https://www.urncst.com! 